\title{
GESTÃO DO PATRIMÔNIO ARQUEOLÓGICO NA AMAZÔNIA: DESAFIOS DA CURADORIA COMPARTILHADA NA REDES DO TUPÉ, MANAUS - AMAZONA
}

\author{
Helena Pinto Lima ${ }^{1}$ \\ Ellen Barbosa Andrade ${ }^{2}$ \\ Carlos Augusto da Silva ${ }^{3}$
}

\section{RESUMO}

Este artigo discute a formação e formas de apropriação de um acervo arqueológico com peças recolhidas por moradores da Reserva de Desenvolvimento Sustentável do Tupé, localizada na zona rural de Manaus/AM. Apresentamos ações do Grupo Interinstitucional "Tupé: Memória, Cultura e Identidade" destacando a formação de um grupo comunitário de cerâmica artesanal; o inventário participativo do acervo e a montagem de uma exposição concebida coletivamente. Durante a experiência, salientaram-se conflitos que evidenciam ambiguidades referentes à coleta (e ao colecionismo), à apropriação e socialização do acervo arqueológico, bem como à legislação de salvaguarda desses bens públicos. Refletindo sobre a experiência, é possível registrar aprendizados concernentes à gestão do patrimônio arqueológico na região amazônica.

PALAVRAS-CHAVE: gestão do patrimônio arqueológico, acervos, colecionismo, curadoria compartilhada, comunidades amazônicas.

\section{ABSTRACT}

This paper discusses the formation of an archaeological collection with objects collected by residents of a community in the Tupe Reserve (REDES do Tupe), situated in the rural zone of the municipality of Manaus/Amazonas state. We present actions by the Interinstitutional Group "Tupe: Memory, Culture and Identity" (Tupe memo) highlighting the formation and consolidation of a productive group of ceramics; a shared curatorship and inventory of the archaeological collection and an exhibition of these artifacts. Conflicts raised throughout the work highlighted many ambiguities within the community, including the relationship between the appropriation and socialization of the collection; the legislation regarding the safeguard of such archaeological goods and the role of the different actors involved in the process. We consider this as a sensitive case, from which we can draw important insights about the management of archaeological heritage in Amazonia.

KEYWORDS: archaeological heritage management, collections, collecting, shared curatorship, Amazonian communities.

\section{RESUMEN}

Este artículo discute la formación y las formas de apropiación de un acervo arqueológico con piezas recolectadas por moradores de la Reserva de Desarrollo Sustentable de Tupé, localizada en la zona rural de Manaus/AM. Presentamos aquí acciones del Grupo Interinstitucional "Tupé: Memoria, Cultura e Identidad" destacando la formación de un grupo

\footnotetext{
${ }^{1}$ Museu Paraense Emílio Goeldi - Coordenação de Ciências Humanas. E-mail: helenalima@museugoeldi.br.

${ }^{2}$ Universidade Federal do Amazonas. E-mail: ellenandrade@ufam.edu.br.

${ }^{3}$ Universidade Federal do Amazonas. E-mail: casilva@ufam.edu.br.

\begin{tabular}{l|l|l|l|l|l|l}
\hline (C) Rev. Arqueologia Pública & Campinas, SP & v.11 & n.2 & p. 114 & Novembro/2017 & ISSN 2237-8294 \\
\hline
\end{tabular}
} 
comunitario productor de cerámica artesanal; el inventario participativo del acervo y el montaje colectiva de una exhibición. Durante la experiencia, se han evidenciado conflictos que destacan ambigüedades referentes a la colecta y al coleccionismo, la apropiación y socialización del acervo arqueológico, como también a la legislación de salvaguarda de bienes públicos. Reflejando sobre esta experiencia, es posible registrar aprendizajes para la gestión del patrimonio arqueológico en la región amazónica.

PALABRAS CLAVE: gestión del patrimonio arqueológico, acervos, coleccionismo, curaduría, comunidades amazónicas.

\section{INTRODUÇÃO}

Este artigo apresenta reflexões sobre o processo de patrimonialização de bens arqueológicos na Amazônia, tomando como estudo de caso uma experiência desenvolvida no âmbito do Grupo Interinstitucional "Tupé: Memória, Cultura e Identidade" (Tupé memo). As ações aqui referidas foram concentradas no distrito da sede da comunidade Agrovila Amazonino Mendes, ou simplesmente Agrovila, uma das seis comunidades estabelecidas sobre sítios de ocupações pretéritas que integram a Reserva de Desenvolvimento Sustentável do Tupé (REDES do Tupé), uma unidade de conservação (UC) municipal localizada na zona rural de Manaus, Estado do Amazonas, Brasil.

A exemplo do que ocorre em uma vasta região do baixo rio Negro e entorno de Manaus, a grande ocorrência de sítios e vestígios arqueológicos encontrados na REDES do Tupé remonta a uma história indígena de longuíssima duração (SIMÕES 1974, LIMA 2008, NEVES, 2012). Além de contarem uma importante parte da história indígena local antes da conquista europeia, esses restos de cultura material e marcas na paisagem contam também aspectos importantes de histórias pessoais a familiares dos moradores dessas áreas, fazendo, assim, parte de seu dia a dia (LIMA e MORAES, 2013). No caso aqui enfoque, vemos uma relação em que a coleta descomedida de artefatos ao longo do tempo gerou um acervo com o qual alguns dos moradores possuem fortes laços de identificação.

Este texto abordará os trabalhos realizados em torno de um acervo de peças arqueológicas e históricas que, desde 2003, vinham sendo recolhidas exclusivamente pelos moradores da comunidade Agrovila e reunidas na escola pública municipal situada nesta comunidade, com o conhecimento dos gestores públicos.

Tendo em vista a importância simbólica, paisagística, turística e econômica da região compreendida por esta UC, parcialmente delimitada pelo igarapé Tarumã-Mirim, um importante afluente do baixo rio Negro, identificou-se a necessidade de oportunizar às comunidades locais ações que discutissem o patrimônio arqueológico local, repercutindo, assim, em sua preservação. Essas demandas partiram da própria sociedade civil e 
chegaram à Universidade Federal do Amazonas (UFAM), mobilizando professores, técnicoadministrativos e alunos.

As ações foram concebidas e desenvolvidas dentro do Programa de Atividades Curriculares de Extensão (PACE) da UFAM por membros do grupo interinstitucional "Tupé: Memória, Cultura e Identidade", ou simplesmente "Tupé memo", no âmbito do Programa Tupé/UFAM, que atua continuamente na REDES do Tupé, desde 1997 até os dias atuais.

Com a proposta de integrar ensino, pesquisa e extensão dentro e fora da universidade, o grupo Tupé memo atuou de 2010 até 2013 na REDES do Tupé com a finalidade de contribuir para a salvaguarda do patrimônio cultural, material e imaterial local, buscando realizar, de modo contínuo, reflexões e ações integradas, envolvendo membros de diversas instituições governamentais e da sociedade civil, principalmente professores e estudantes do ensino fundamental, médio e superior, técnicos e profissionais de várias áreas do conhecimento, gestores públicos, artesãos e lideranças comunitárias (ANDRADE et al., 2013).

Ao longo dos três anos de atuação no distrito da sede da Agrovila, foram alcançados resultados significativos, destacando-se a formação de um grupo comunitário de cerâmica artesanal; um inventário obtido a partir da curadoria compartilhada do acervo existente na escola pública local; a produção de materiais de apoio a partir de oficinas de arqueologia e de educação patrimonial, culminando com um processo participativo de concepção, viabilização, montagem e realização de uma mostra de itens arqueológicos e de produção cerâmica local, realizada no Museu Amazônico da UFAM, entre novembro de 2012 e janeiro de 2013, também com curadoria participativa.

Durante a experiência, salientaram-se conflitos que tornaram evidentes muitas ambiguidades, sobretudo referentes à coleta e ao colecionismo, à apropriação e à socialização do acervo arqueológico, bem como quanto a alguns aspectos da legislação de salvaguarda desses bens públicos. Portanto, acreditamos que refletindo sobre tal experiência, seja possível registrar aprendizados e construir conhecimentos concernentes à gestão do patrimônio arqueológico na região amazônica.

Assim, a relação entre pesquisadores, gestores e moradores reverteu-se em um quadro delicado no que se refere ao manejo e gestão da coleção arqueológica, que está sob a guarda da Escola Municipal Paulo Freire, na sede da comunidade Agrovila. Os conflitos, que foram acompanhados pelo IPHAN e pelo Ministério Público, gerados em torno da "posse" dos objetos históricos e arqueológicos redundaram, entre outras consequências, na paralisação da atuação do grupo Tupé memo naquela localidade, em 2013. 
Conflitos como o mencionado, que colocam em cheque a questão "Quem tem direito à coleção arqueológica?", podem ensinar muito a todos os agentes e agências envolvidos nas ações, mas, igualmente, refletem a fragilidade dos mecanismos legais e da gestão pública para com o patrimônio arqueológico, histórico e cultural.

O presente artigo está organizado da seguinte maneira: inicialmente se apresentará a REDES do Tupé, suas comunidades e potencialidades arqueológicas; o Grupo Interinstitucional TUPÉ MEMO, seus parceiros, objetivos e histórico, assim como as ações ligadas especificamente à Arqueologia e à Educação Patrimonial no distrito da sede da comunidade Agrovila, da REDES do Tupé e, por fim, torna públicas algumas das inquietações relacionadas à salvaguarda do acervo e à preservação dos sítios arqueológicos existentes naquela UC.

Considerando a postura de alguns arqueólogos que entendem a natureza eminentemente política da atuação arqueológica, constituindo-se assim num poderoso instrumento de ação política e social (BEZERRA, 2011, p. 62), nem sempre as variáveis dessa atuação são de pleno conhecimento e, menos ainda, de controle por parte dos diferentes agentes envolvidos - dos moradores e suas relações e demandas individuais e coletivas, arqueólogos-pesquisadores e outros profissionais, professores, estudantes, sobretudo dos gestores públicos. Trata-se, aqui, de uma experiência empírica pontual, que versa sobre arqueologia, mas que pode ensinar para diversos outros campos das ciências humanas, que cada vez mais têm se dedicado a pensar sua impossível imparcialidade (GNECCO, 2009; TROUILLOT, 2011).

\section{A REDES DO TUPÉ, SUAS COMUNIDADES E SíTIOS ARQUEOLÓGICOS}

A Reserva de Desenvolvimento Sustentável do Tupé (REDES do Tupé), com cerca de 12.000 hectares, está localizada na área rural de Manaus-AM, situando-se a aproximadamente $25 \mathrm{~km}$, em linha reta, da área urbana deste município. Sua gestão está ao encargo da Secretaria Municipal de Meio Ambiente e Sustentabilidade (SEMMAS) de Manaus e do Conselho Deliberativo da REDES do Tupé, em funcionamento contínuo desde 2006.

A REDES do Tupé, segundo Chateaubriand et al. (2009), abriga 18 distritos distribuídos em seis comunidades - Agrovila, Central, Julião, Livramento, São João e Tatu, havendo ainda, no entorno dessa reserva, outras sete comunidades rurais, todas ocupadas por populações tradicionais, incluindo indígenas.

Em face da inexistência de rodovias, o deslocamento da área urbana de Manaus até as comunidades da REDES do Tupé, como também a circulação entre as próprias e entre \begin{tabular}{|l|l|l|l|l|l|l|}
\hline (c) Rev. Arqueologia Pública & Campinas, SP & v.11 & n.2 & p. 117 & Novembro/2017 & ISSN 2237-8294 \\
\hline
\end{tabular} 
seus respectivos lotes, são feitas por trilhas percorridas a pé ou principalmente por via fluvial, utilizando-se os cursos d'água ali existentes, em cujas margens e proximidades estão localizadas a maioria dessas populações (ANDRADE et al., 2004).

Chateaubriand et al. (2009) mostram que a REDES do Tupé está situada à margem esquerda do rio Negro, na confluência com o Tarumã-mirim, possuindo uma rica hidrografia, destacando-se os igarapés do Tupé, do Tatu, das Acácias, Julião, Caniço, dentre vários outros cursos d'água locais.

O termo "REDES" ao invés de "RDS" como acrônimo para "Reserva de Desenvolvimento Sustentável" foi proposto pelo Programa Tupé da UFAM com as justificativas de que: 1) o termo foi adotado no texto da Lei Municipal e nos documentos legais daquela UC (MANAUS, 2005); b) REDES tem forte simbologia regional, uma vez que o termo designa utensílios fortemente relacionados às tradições amazônicas e c) REDES tem significado educativo, destacando a relevância das redes de agentes e agências sociais para viabilização do desenvolvimento sustentável, construídas coletivamente a partir de um mesmo objetivo, de contribuições individuais e de reflexões coletivas (CHATEAUBRIAND et al., 2009).

Além da predominância da floresta ombrófila úmida típica de ambientes de terra firme na Amazônia, a vegetação da região comporta também florestas de baixio, campinas e campinaranas. Os solos de campinarana e baixio correspondem respectivamente a areias quartzosas álicas e solos arenosos (ARRUDA, 2005 apud GONÇALVES, 2011).

Com exceção da comunidade Central, que não possui acesso direto ao rio Negro, as demais comunidades da reserva estão assentadas sobre sítios arqueológicos, são todas formadas por solos antropogênicos (terra pretas) e possuem fragmentos de cerâmica aflorando na superfície (CALHEIROS et al., 2014). São registrados nove sítios arqueológicos dentro e nos arredores da reserva, apontando para o elevado potencial arqueológico da região, dos quais apenas seis constam no Cadastro Nacional de Sítios Arqueológicos (CNSA) do IPHAN. Eles se situam nas proximidades de igarapés como o Tarumã-Açu e Tarumã-Mirim, além do próprio baixo curso do rio Negro. São eles: Arara, Carvoaria, Tatu, Tupé, Boca do Tupé (Comunidade São João), Praia Dourada, Agrovila Amazonino Mendes, Julião e Livramento (NEVES, 2000, 2003, 2005; COSTA e LIMA, 2006; SILVA, 2008; CALHEIROS et al., 2014). 


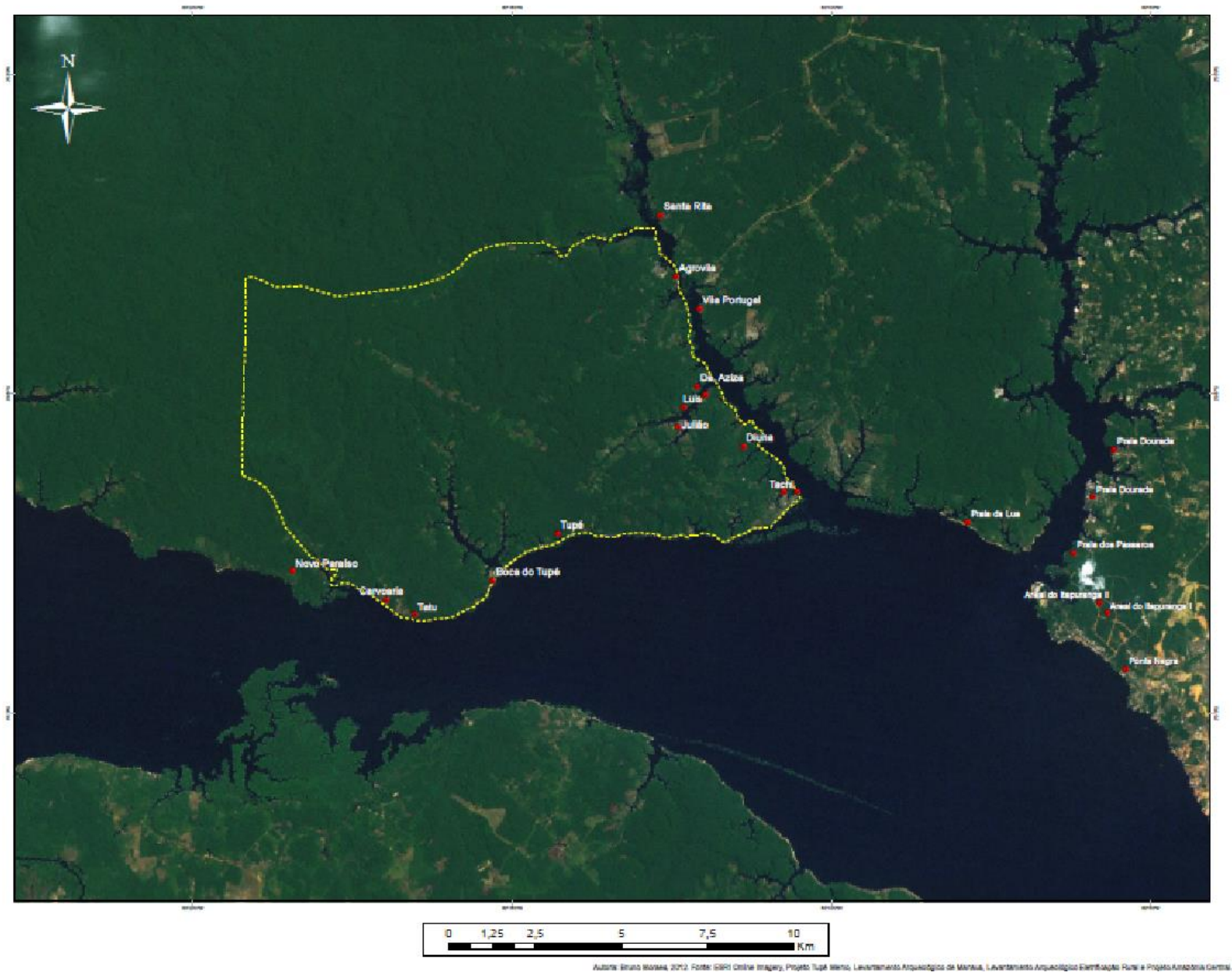

FIGURA 1: Mapa de localização da REDES do Tupé e sítios arqueológicos identificados dentro e no entorno dessa UC (Mapa: Bruno Moraes, 2012).

Até o início da atuação do Tupé memo, três projetos de pesquisa arqueológica de maior envergadura e relevância já haviam atuado na região, a saber: Projeto Amazônia Central (PAC); Projeto Levantamento Arqueológico no Município de Manaus (LAMA) e o Licenciamento ambiental para implantação do Programa federal Luz para Todos.

A identificação inicial de sítios foi realizada nos primeiros anos de atuação do Projeto Amazônia Central, desenvolvido pelo Museu de Arqueologia e Etnologia da Universidade de São Paulo (MAE/USP) a partir do ano de 1995 (NEVES, 2000; 2003; 2005). Desde então até 2010 , esse projeto atuou com uma equipe multidisciplinar, contando com pesquisadores e estudantes de diversas instituições nacionais e internacionais, e veio colocar esta importante região amazônica, constantemente debatida desde a década de 1960, entre as áreas da Amazônia brasileira melhor conhecidas arqueologicamente na atualidade (LIMA, 2008; NEVES, 2012). 
Posteriormente, houve uma atuação do IPHAN, enquanto órgão gestor e responsável pela salvaguarda do patrimônio arqueológico nacional, visando ao cadastro e o georreferenciamento dos sítios e coleções arqueológicas localizados no município de Manaus. Surgiu então o projeto "Levantamento Arqueológico no Município de Manaus" (LAMA), realizado em 2005-2006, responsável pela identificação de trinta e cinco sítios nas áreas urbana e rural de Manaus, incluindo alguns dos sítios da REDES do Tupé que foram devidamente cadastrados (COSTA e LIMA, 2006). Costa e Lima (2006) relatam que, no sítio Boca do Tupé, localizado junto à comunidade indígena e ribeirinha São João, os materiais cerâmicos associados às fases Guarita e Paredão afloram na superfície. A Figura 2a mostra imagem in loco de dois recipientes cerâmicos fragmentados, um assador e um alguidar, localizados por ocasião de escavações para construção de uma casa de força na comunidade. Após contatos com comunitários, os fragmentos foram transportados, junto aos professores da escola pública local, deixando-os disponíveis nesta mesma escola.

Em um período mais recente, Silva (2008) relata que foram realizadas prospecções arqueológicas na REDES do Tupé, incluindo escavações naquela reserva, no âmbito do licenciamento ambiental para implantação do Programa Luz Para Todos, do governo federal, em três comunidades daquela UC - Agrovila, Julião e Livramento. Na época, foi realizado o resgate (exumação) de um recipiente cerâmico na comunidade Livramento (Figura 2b), o qual se encontra atualmente sob a guarda da UFAM, instituição de apoio e guarda do estudo.

Destaca-se que a atuação de tais projetos de pesquisa e gestão arqueológicas na região proporcionaram aos moradores do Tupé diferentes formas de contato com equipes de arqueólogos, cadastrando sítios, escavando seus terrenos e movimentando seus acervos. Para além disso, assim como em outras partes do interior ribeirinho da Amazônia, os materiais arqueológicos não deixam de fazer parte das vidas das pessoas que vivem nessas comunidades rurais (LIMA e MORAES, 2013). Muitas vezes, as peças são recolhidas, guardadas e expostas em pequenos museus comunitários, como foi visto na comunidade Agrovila, que é o foco deste artigo. 

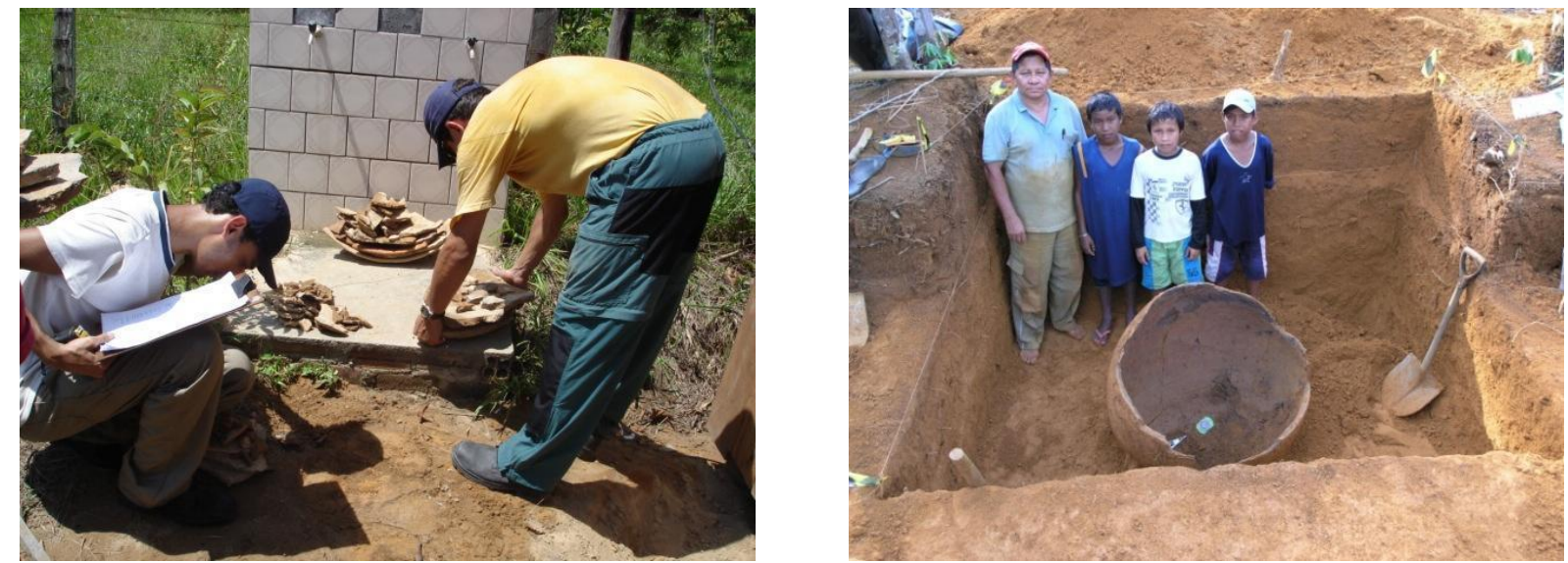

FIGURA 2: A) Sítio Boca do Tupé, onde um assador e um alguidar de cerâmica foram acomodados na escola pública da comunidade, para remontagem e exibição (Fonte: COSTA E LIMA, 2006); B) recipiente cerâmico exumado em 2008 na comunidade Livramento, REDES do Tupé (Fonte: SILVA, 2008).

$\mathrm{Na}$ interação com as comunidades da reserva do Tupé observou-se uma antiga - e crescente - prática de coleta e apropriação de referências culturais indígenas como uma forma de patrimonialização de suas origens, com fins diversos, entre eles, turísticos. Um exemplo disso é a comunidade São João, onde se estabelece uma população indígena principalmente das etnias Tukano, Desana, e Tuyuca, descida do alto rio Negro, com a construção de uma maloca tradicional, a apresentação de rituais aos turistas, especialmente estrangeiros, e a venda de artesanato.

O turismo no Tupé tem grande repercussão em níveis local, regional e também internacional. É uma região de enorme beleza paisagística, com excelentes praias para banho. Em entrevista com o gestor desta UC entre os anos de 2005 a 2008, Palmeira (2009, p. 116) reproduz que o Tupé vinha sendo "historicamente visitado por turistas e recreadores de fim de semana". De fato, é possível visualizarmos a REDES do Tupé na maior parte dos roteiros turísticos oferecidos na cidade de Manaus. Em relação à atividade de turismo e lazer, a comunidade São João do Tupé já recebeu vários projetos de capacitação, incluindo oficinas de reciclagem de resíduos, educação ambiental, e ecoturismo (PEIXOTO, 2013, p. 16). No entanto, conforme apontado por Peixoto, "ainda não se vê os resultados práticos desses projetos nem há qualquer movimento para a organização em associação para a gerência do turismo de natureza ou o ecoturismo" (2013, p. 17), o que torna a situação preocupante. 


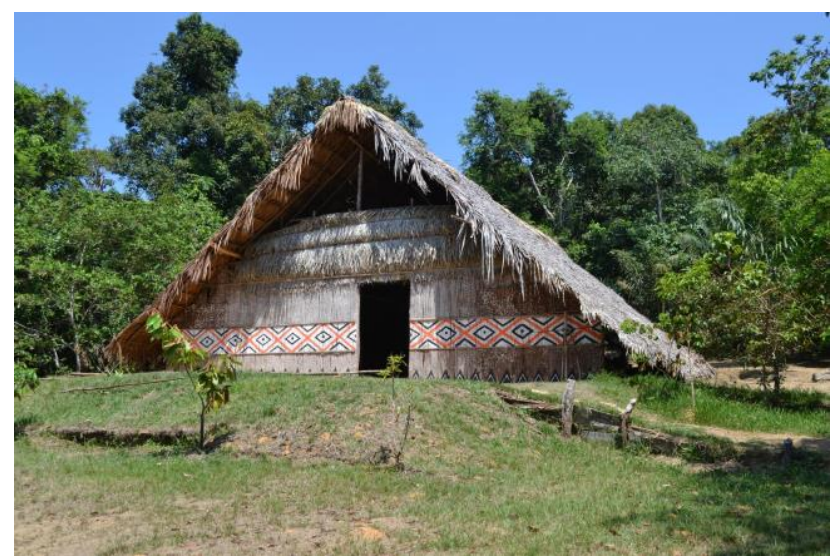

FIGURA 3: Maloca onde indígenas recebem visitantes na comunidade São João do Tupé, assentada sobre área de terra preta (Fonte: LIMA e ANDRADE, 2013).

Alguns arqueólogos têm debatido a questão do crescente turismo em áreas arqueológicas (PEREIRA e FIGUEIREDO, 2005; LIMA et al., 2013; GODOY, 2016). Pereira e Figueiredo, ainda em 2005, alertam para a forma como "os sítios arqueológicos brasileiros passaram a ser considerados como uma opção de turismo [...] Visitados inicialmente de maneira informal, rapidamente alguns sítios arqueológicos passaram a fazer parte de roteiros turísticos na região amazônica" (2005, p. 23). Eles alertam para o risco que este tipo de prática oferece ao patrimônio arqueológico, argumentando que, na própria composição do produto turístico, os itens da natureza e da cultura passam a ter um valor, podendo, assim, serem alvos de comercialização.

É evidente que o turismo pode ser revertido em fator de conservação do patrimônio arqueológico, desde que sejam tomadas medidas apropriadas para o manejo dos sítios (idem). Nessa mesma linha, Godoy (2016) propõe o turismo arqueológico como uma ferramenta de preservação cultural. A autora ainda salienta que a atuação arqueológica com interface direta ao público seja uma forma de antropologia aplicada (idem). A pesquisa aplicada, ou pesquisa-ação, tal como definida por Thiollent (2011), tem como foco a resolução de problemas específicos da sociedade. Sendo este o caso da nossa atuação em uma das comunidades da REDES do Tupé.

O trabalho em questão foi concentrado principalmente na sede da comunidade Agrovila Amazonino Mendes, considerando-se que, naquela localidade, foi identificada uma iniciativa comunitária pioneira relacionada a um importante acervo de peças arqueológicas e históricas, desde 2004 sob a guarda da Escola Municipal Paulo Freire, da Secretaria Municipal de Educação (SEMED), e, como mencionamos, com o conhecimento do IPHAN. 


\section{O GRUPO INTERINSTITUCIONAL TUPÉ MEMO E ALGUMAS AÇÕES}

Além das pesquisas arqueológicas relatadas, tem-se conhecimento também de que em 2009 diversos setores da Secretaria de Educação do Município de Manaus (SEMED) envolveram-se na realização de atividades de socialização do patrimônio arqueológico e de educação patrimonial na REDES do Tupé, culminando na criação do Memorial Paulo Freire, vinculado e instalado na escola pública municipal de mesmo nome, na comunidade Agrovila. A partir do início de 2010, tais ações tiveram continuidade por meio de articulação da SEMED com o Programa Tupé da UFAM, responsável à época pela realização da formação de comunitários em técnicas artesanais em cerâmica (LIMA e ANDRADE, 2013).

Essa articulação foi a semente que deu origem, em 2010, ao grupo interinstitucional denominado "Tupé: memória, cultura e identidade", o "Tupé memo", concebido e estruturado como rede social de reflexão e ação conjunta de agentes e agências da sociedade, interessados em contribuir para a proteção do patrimônio cultural, material e imaterial, da REDES do Tupé (ANDRADE et al., 2013).

Era então de conhecimento que, além das pesquisas naquela reserva, havia urgência em desenvolver atividades de socialização do patrimônio arqueológico e de educação patrimonial, posto que essas ações são um importante vetor que possibilita a discussão, com a população local, as necessidades, possibilidades e estratégias para o manejo dos sítios e coleções arqueológicas.

O grupo Tupé memo buscou, desde sua criação, ser um fórum e espaço social permanentes de concepção e viabilização de ações que, por um lado, promovessem a valorização e a integridade do patrimônio, entendendo que as comunidades do Tupé são as guardiãs por excelência dos sítios locais e de seu conteúdo.

Assim, pesquisas na comunidade Agrovila tiveram um caráter aplicado, já que visaram a aplicação prática, com o objetivo de atender a exigências e à solução de questionamentos específicos (LIMA e ANDRADE, 2013). Dessa forma, a compreensão de como os comunitários se relacionam com seu patrimônio contribuiu para sugestões de desdobramentos de pesquisas arqueológicas que, em última instância, poderiam ajudar na contenção de problemas bastante comuns na Amazônia, como a destruição dos sítios ou a utilização indevida de vestígios da cultura material por desconhecimento ou falta de informações.

A opção do Tupé memo em iniciar as ações no sítio e comunidade Agrovila e pouco a pouco expandir-se para outros sítios e comunidades dessa reserva ambiental se deu em função das já mencionadas ações comunitárias iniciadas na Escola Municipal Paulo Freire, no sentido da salvaguarda do acervo arqueológico ali existente. 
Assim, passou-se então a desenvolver ações em arqueologia e educação patrimonial na REDES do Tupé, com uma proposta de uma pesquisa arqueológica de caráter participativo visando promover um programa de educação patrimonial com uma série de ações ligadas à socialização do patrimônio arqueológico junto às comunidades da REDES do Tupé. Estas ações envolveram oficinas e palestras junto ao Conselho Deliberativo da reserva, professores e estudantes da SEMED, e membros da SEMMAS.

As atividades propostas reverteriam-se num vetor que possibilitaria a discussão com a população local sobre as necessidades e possibilidades do manejo dos sítios e coleções arqueológicas. Os objetivos foram, por um lado, garantir a própria integridade futura do patrimônio, uma vez que a comunidade é a guardiã por excelência do sítio e de seu conteúdo, e, por outro, promover condições que permitissem à comunidade a exploração desse patrimônio que gerasse captação de renda, por exemplo, por meio de um turismo arqueológico consciente, da produção de cerâmica artesanal orientada, sobretudo à valorização e consequente preservação do patrimônio.

\section{OFICINAS E PALESTRAS DE ARQUEOLOGIA E EDUCAÇÃO PATRIMONIAL}

Foram realizadas diversas ações de assessoramento e de capacitação, envolvendo professores e estudantes do ensino fundamental, médio e superior, como também de comunitários em geral, abordando conteúdos teóricos e metodológicos da arqueologia, na expectativa de transformá-los em células multiplicadoras da discussão e do conhecimento arqueológico, visando à valoração do patrimônio cultural local e regional e a formação de uma população crítica, conforme sugerido por Horta et al. (1999), há tempos, mas apoiando-se também em trabalhos anteriores na região amazônica, como os de Gibertoni (2009), Lima e Parente (2009) e Lima et al. (2013).

As atividades envolveram o assessoramento no planejamento e na elaboração de material educativo específico, impresso e audiovisual, bem como a realização de palestras, que ocorreram paralelamente a oficinas de aplicação prática dos conteúdos trabalhados e simultaneamente a outras ações do grupo interinstitucional Tupé memo, numa estratégia que se mostrou fundamental para que fossem discutidas, com a comunidade, as necessidades e possibilidades do manejo dos sítios e coleções arqueológicas.

A realização das palestras no Conselho Deliberativo e nas comunidades São João e Agrovila envolveram respectivamente lideranças comunitárias e gestores, pesquisadores, professores e estudantes das quatro escolas públicas municipais dessa reserva e, no final de 2012, ocorreu no contexto de um programa de educação patrimonial, planejado no âmbito do grupo Tupé memo e institucionalizado pela SEMED (LIMA e ANDRADE, 2012). 


\section{HIGIENIZAÇÃo DE PEÇAS E INVENTÁRIO PARTICIPATIVOS DE ACERVO ARQUEOLÓGICO}

Os resultados mais significativos ocorreram nas atividades participativas para higienização e inventário da coleção arqueológica existente na Escola Municipal Paulo Freire, quando foram catalogadas 154 peças arqueológicas e históricas, perfazendo a maior parte do acervo.

Vale ressaltar que, na Escola Municipal Paulo Freire, local de guarda desse acervo, até meados de 2011, quando foram iniciadas as atividades desse inventário participativo, não havia nenhum registro impresso de catalogação das peças dessa coleção, cujos dados e informações encontravam-se apenas na memória de pouquíssimos moradores da Agrovila, sendo repassadas oralmente a visitantes e interessados, exclusivamente por um morador local e professor da SEMED, gestor da escola entre 2003 e 2011, período em que liderou a iniciativa comunitária de reunir as peças, guardando-as na escola.

Nesse inventário participativo, buscou-se seguir diretrizes do IPHAN e do setor de curadoria Museu Amazônico da UFAM, previamente apresentadas e demonstradas em oficinas com os comunitários da Agrovila e demais envolvidos nos procedimentos, abrangendo aspectos relacionados à limpeza, numeração, identificação e posterior classificação das peças, assim como seu acondicionamento.

A ficha modelo, elaborada para a catalogação das peças, possuía campos para preenchimento dos seguintes dados: data em que a peça passou a integrar a coleção; número; nome; dimensões e descrição da peça; nome do coletor e/ou doador da peça; local de coleta da própria, além de um campo para outras observações necessárias.

Cada uma das 154 fichas produzidas na catalogação desses artefatos foi preenchida exclusivamente com informações fornecidas pelos comunitários moradores da Agrovila e, em sua maioria, foram manuscritas pelo professor supracitado, que coordenou esse processo na comunidade e repassou, posteriormente, tais fichas manuscritas à coordenação do Programa Tupé da UFAM. Os originais destas fichas manuscritas foram devolvidos pela UFAM ao autor das próprias, após sua reprodução em cópias.

A atividade envolveria, ainda, um inventário arqueológico da região, em sentido mais amplo, referenciando sítios e paisagens de importância da região, mas esta segunda etapa não se concretizou, embora seja fundamental para registro e conhecimento do acervo arqueológico local, podendo remeter a importantes informações sobre a história pré-colonial local e regional, constituindo-se num importante instrumento para estudos e pesquisas em arqueologia. 


\section{Revista de Arqueologia Pública}
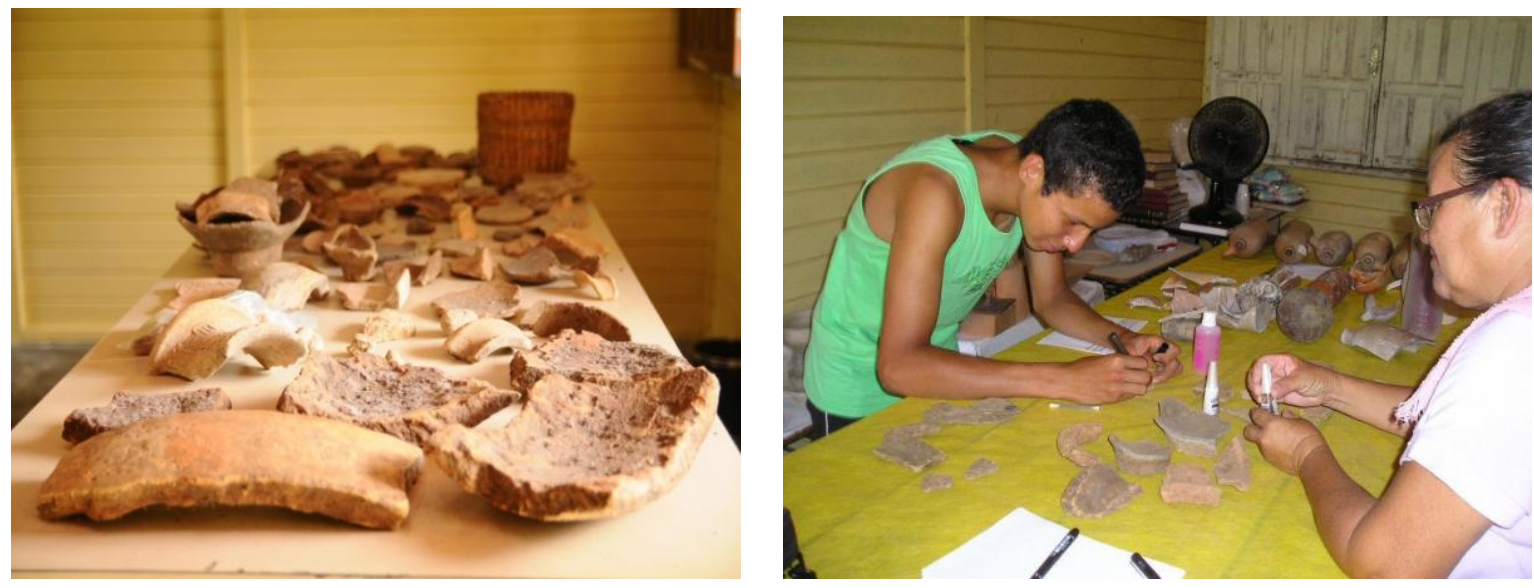

FIGURA 4: A) Peças da comunidade Agrovila, guardadas na escola pública local, antes das intervenções da UFAM e do grupo Tupé memo (Fonte: acervo IPHAN/AM); B) oficina de arqueologia, curadoria e inventário participativo da coleção, realizada em 2011, na Escola Municipal Paulo Freire, na Agrovila, sob orientação de equipe do Museu Amazônico da UFAM (Fonte: acervo Tupé memo,

UFAM).

Após a conclusão dos trabalhos nesse inventário participativo em 2011, observou-se que até o final de 2012 a comunidade e a escola local não haviam dado continuidade ao referido inventário, apesar de outras peças arqueológicas terem sido incorporadas a tal acervo, por iniciativa exclusiva de algumas lideranças comunitárias, sem participação da equipe da UFAM.

\section{A EXPOSIÇÃO “TUPÉ: MEMÓRIA, CULTURA E IDENTIDADE” E A EVIDENCIAÇÃO DOS CONFLITOS}

A proposta de realizar uma exposição das peças arqueológicas e históricas existentes na Escola Municipal Paulo Freire foi recebida com grande entusiasmo por lideranças e artesãos de cerâmica da comunidade Agrovila, como também pela SEMED, escolhendo-se, então, para sediar o evento, o Museu Amazônico da UFAM, localizado no centro histórico da área urbana de Manaus.

A exposição teria a finalidade de mostrar não somente peças arqueológicas, históricas e contemporâneas da Agrovila, mas apresentar também à sociedade as diversas ações conjuntas desenvolvidas pelo Tupé memo, com o objetivo de valorização do patrimônio cultural das comunidades rurais situadas na REDES do Tupé e seu entorno. Nesse sentido, foi definido que a exposição "Tupé: memória, cultura e identidade" teria como eixo curatorial as dimensões "Passado, Presente e Futuro", conforme a seguir:

a) Passado - mostra de peças arqueológicas, históricas e paleontológicas, juntamente a painéis (banners) abordando aspectos da Arqueologia e da História regional;

\begin{tabular}{|l|l|l|l|l|l|l|}
\hline (C) Rev. Arqueologia Pública & Campinas, SP & v.11 & n.2 & p. 126 & Novembro/2017 & ISSN 2237-8294
\end{tabular}


b) Presente - mostra de peças contemporâneas de artesanato em cerâmica, réplicas em cerâmica de peças arqueológicas e outras peças cerâmicas de inspiração arqueológica, todas confeccionadas por artesãos moradores da Agrovila e adjacências; exibição de fotografias ampliadas e de diversos painéis com textos e imagens, abordando aspectos gerais e mapeamento da REDES do Tupé, como também informações gerais sobre o grupo;

c) Futuro - mostra audiovisual (projeção de vídeos) abordando propostas e ações então em andamento e planejadas no âmbito do grupo interinstitucional Tupé memo.

Paralelamente à exposição, pensou-se também em promover a comercialização da produção artesanal em cerâmica da comunidade Agrovila, contudo, foi decidido não incluir tal empreendimento, considerando que os artesãos ainda não se sentiam devidamente preparados para ele e que essa ideia poderia ser colocada em prática numa outra oportunidade.

A partir de então, desencadeou-se o processo para planejamento e organização dessa exposição, envolvendo principalmente lideranças e artesãos da comunidade Agrovila, a Escola Municipal Paulo Freire e outros setores da SEMED, além de equipes do Museu Amazônico e do Programa Tupé, todos trabalhando em conjunto nas diversas etapas e procedimentos preparatórios e executivos do evento, até o seu encerramento.

Inaugurada para o público em novembro de 2012, a exposição "Tupé: memória, cultura e identidade" esteve em cartaz até o final de janeiro de 2013. Acreditamos que esta exposição cumpriu o propósito original de comunicar e socializar o conhecimento dialógico, alcançando o público-alvo esperado - principalmente comunitários, pesquisadores, professores e estudantes dos diversos níveis de ensino, do fundamental ao superior -, como também cumpriu seus fins educativos, na medida em que sensibilizou a todos, organizadores e visitantes, para a causa da proteção do patrimônio cultural, material e imaterial da REDES do Tupé.

$\mathrm{Na}$ abertura da exposição, foi realizada a exibição de um audiovisual produzido pelo grupo interinstitucional Tupé memo, com depoimentos de líderes comunitários, moradores, artesãos ceramistas da comunidade Agrovila, os quais destacaram a relevância das ações de educação patrimonial desenvolvidas na Agrovila e a importância do apoio das instituições que atuam nessa temática, naquela comunidade. Foram convidados a se pronunciar os líderes e professores dessa comunidade, assim como representantes do Museu Amazônico, da Universidade e do Grupo Tupé memo. Foi possível ver a alegria e o orgulho de muitos dos moradores do Tupé em muitos dos depoimentos dados às redes de televisão de Manaus, que cobriram o evento. 
Os visitantes da exposição - professores, estudantes, pesquisadores, turistas brasileiros, estrangeiros e outros interessados, sempre foram recepcionados e guiados pelo professor da comunidade Agrovila, responsável pela formação do acervo. Quando o professor não se encontrava no Museu Amazônico, a equipe do museu cumpria esse papel.

Buscou-se, sempre que possível, que artesãos e moradores da Agrovila protagonizassem todas as atividades da exposição, principalmente durante a visitação, aspecto considerado fundamental para valorização do acervo exposto e continuidade e ampliação das ações conjuntas realizadas ao longo de três anos naquela comunidade pelo grupo.

De um modo geral, a visitação a essa exposição foi bem-sucedida, pois, durante quase três meses em que esteve em cartaz, foram registradas cerca de oitocentas assinaturas no Livro de Registro de Presença do Museu Amazônico feitas por pessoas de diversas origens - brasileira e estrangeira. Contudo, apesar do sucesso em termos objetivos do empreendimento, no decorrer das etapas algumas situações delicadas passaram a compor o cenário.

Quanto à seleção dos materiais que compuseram a mostra, estes foram escolhidos em conjunto peças arqueológicas inteiras e fragmentos de cerâmicas e líticos, apontando uma sequência cronológica de longa duração, na ocupação pretérita da área. Foram selecionadas, também, peças históricas, como algumas garrafas de grés, evidenciando a área como locus de contato entre identidades indígenas e europeias e uma escultura histórica em madeira. Por fim, também foram selecionadas peças representativas do artesanato da Agrovila, produzidas recentemente nessa comunidade. Porém, quanto às últimas, não houve consenso a respeito da inclusão dessas peças contemporâneas, confeccionadas por artesãos da Agrovila durante sua participação na formação em técnicas artesanais de cerâmica. O professor e alguns poucos artesãos consideravam que tais peças eram imperfeitas e requeriam aprimoramento, discordando à época das equipes da UFAM e da SEMED e dos demais artesãos, os quais eram favoráveis a expô-las, parte da produção inicial do novo grupo ceramista da Agrovila, como forma de incentivar a consolidação deste grupo. Ao final, decidiu-se por expor somente as peças daqueles artesãos que concordaram em ter seu trabalho divulgado por meio da exposição.

No que se refere às três peças paleontológicas incluídas nessa exposição, é importante relatar que elas se encontravam na UFAM, em 2012, devido ao fato de terem sido emprestadas pelo mesmo professor da Escola Municipal Paulo Freire a professores do Departamento de Geociências da UFAM, alheios ao Programa Tupé, em um período anterior às ações do grupo interinstitucional Tupé memo ligadas ao acervo da Agrovila. No 
entanto, por ser da mesma universidade, a devolução de tais peças emprestadas era constantemente reclamada pelo professor à equipe da UFAM que atuava na Agrovila.

Buscando solucionar esse problema, a equipe da UFAM envolvida na organização dessa exposição envidou diversos esforços no sentido de providenciar a devolução dessas peças, o que que ocorreu em 2012. As peças foram incluídas na exposição para que fossem novamente incorporadas à coleção da Agrovila e assim devolvidas à comunidade ao término da exposição.

Porém, ao final desse processo, tomou-se conhecimento, por meio de declarações do professor responsável pelo empréstimo, que um dos fósseis teria "reaparecido" fragmentado, na exposição do Museu Amazônico.

Assim, instaurava-se um clima de instabilidade e desconforto entre os membros do Tupé memo e alguns dos moradores da comunidade. O conflito resultou em ação pública do Ministério Público Federal (MPF) envolvendo a universidade e a comunidade, e foi intermediado pelo IPHAN, que acompanhou a desmontagem da exposição e devolução das peças ao seu local de origem, e, atualmente, o memorial Paulo Freire segue com a exposição do acervo em questão.

\section{DESAFIOS DA GESTÃO DO PATRIMÔNIO CULTURAL}

A exposição "Tupé: memória, cultura e identidade" teve como objetivo mostrar algumas facetas da cultura ribeirinha amazônica, a partir da realidade vivida pelos moradores das comunidades localizadas na REDES do TUPÉ, sobretudo no que tange ao patrimônio arqueológico daquela localidade e aos indícios de relações identitárias locais entre passado e presente, evidentes no acervo arqueológico formado por iniciativa exclusivamente dos moradores. Sabe-se que o ato de colecionar e a lógica subjacente que fundamenta uma curadoria e organiza uma exposição não se fazem fora do campo da dominação colonial da geopolítica e de uma cronopolítica (FABIAN, 2010). As lógicas do colecionismo perpassam perspectivas individuais (TROUFLARD, 2017) e coletivas (BEZERRA 2011, BEZERRA E NAJAR 2009), com contextos, finalidades e consequentes significados, muito diversos.

Observa-se que a situação na Agrovila converge para um debate acerca da gestão desse patrimônio, envolvendo, de um lado, o processo comunitário de patrimonialização e de construção ideológico-identitária em esfera local, e por outro lado, os conflitos entre essa comunidade e as instituições governamentais atuantes naquela área, buscando implementar políticas públicas. Este processo, considerado de vital importância para a garantia da integridade das diversidades, simultaneamente históricas, culturais e naturais, requer acompanhamento e intervenções adequadas, sempre que necessário, visando \begin{tabular}{|l|l|l|l|l|l|l|}
\hline (C) Rev. Arqueologia Pública & Campinas, SP & v.11 & n.2 & p. 129 & Novembro/2017 & ISSN 2237-8294
\end{tabular} 
também à correta aplicação dos preceitos legais e da construção da cultura local e regional de proteção do patrimônio material e imaterial brasileiro.

No Brasil, sítios e coleções arqueológicas são classificados como patrimônio material e considerados bens da União, na forma estabelecida pela Lei $\mathrm{N}^{\circ} 3.924 / 61$, que "dispõe sobre os monumentos arqueológicos e pré-históricos", assim como questões referentes à identificação, salvaguarda, restauração, fiscalização e revitalização dos monumentos, sítios e bens móveis do país são dessa alçada, enquanto que a expedição de portarias que autorizam a realização de pesquisas arqueológicas são de competência do IPHAN.

Lima e Parente (2009) discutem como processos de patrimonialização envolvem conflitos inerentes à sociedade, e que, portanto, as políticas públicas voltadas para sua salvaguarda devem torná-los clara e amplamente explícitos. Desse modo, considera-se que a situação do acervo arqueológico da comunidade Agrovila, atualmente sob a guarda da SEMED, na Escola Municipal Paulo Freire, na Agrovila, configura-se como um caso extremamente ambíguo e delicado de gestão desse patrimônio, conforme exposto.

É importante lembrar que a gestão patrimonial é em si fonte de intensos debates, pois não há unanimidade, entre os grupos formadores da nação, sobre o que deve ser objeto de políticas de salvaguarda, sobre como gerir esse patrimônio e quais os critérios a serem utilizados ou mesmo por que fazê-lo. Não obstante, o conflito produtivo entre órgãos da União e representantes da sociedade civil (estejam eles organizados ou não), em muito tem contribuído para que seja traçado um caminho de inclusão social e revisão histórica de supressões culturais (LIMA e PARENTE, 2009).

Nesse sentido, alguns pontos importantes devem ser ressaltados. Primeiramente, acredita-se que ações de base comunitária em prol da proteção e salvaguarda do patrimônio arqueológico e cultural devem ser reconhecidas e estimuladas. Nesse aspecto, a iniciativa pioneira da comunidade Agrovila e da escola local, para guarda do acervo em tela, foi um estímulo para que a UFAM se aproximasse com o intuito de fortalecer e consolidar as iniciativas já existentes na comunidade. É importante ressaltar que tal aproximação não ocorreu como instituição isolada, pelo contrário, desde o início de sua atuação a UFAM buscou constituir um grupo multidisciplinar e interinstitucional, o grupo Tupé memo, uma rede social de atuação contínua e integrada, cuja finalidade, objetivos e método vinham sendo construídos coletivamente ao longo de mais de três anos, envolvendo representações governamentais e da sociedade civil, especialmente organizações e lideranças da Agrovila. 
Ao mesmo tempo em que a atitude pioneira dos moradores e da escola pública da Agrovila, em relação a esse patrimônio local, foi sem dúvida nenhuma muito louvável e desejável, também é fundamental alertar para o fato de que a situação parece ter se revertido em um quadro preocupante de apropriação indevida desse acervo por determinadas pessoas, e não por um coletivo social, podendo abrir graves precedentes para que o acervo deixe de servir à sociedade (uma vez que este patrimônio é bem da União), além de se converter, intencionalmente ou não, em atitudes negativas e indesejáveis, tais como o estímulo ao saque dos sítios arqueológicos da região.

Exemplo disso foi a retirada de um enorme bloco de um afloramento rochoso da área, contendo polidores arqueológicos, o qual foi novamente transportado para a escola por iniciativa exclusiva de moradores da Agrovila, sem qualquer participação da UFAM, do IPHAN, da SEMMAS e do grupo Tupé memo. Essa atitude é ilegal e contradiz qualquer princípio de preservação do patrimônio, colocando em xeque as demais iniciativas comunitárias. Constatou-se, também, que novas peças arqueológicas foram incorporadas ao acervo existente, inseridas após a conclusão do processo participativo de catalogação de parte da coleção, situação delicada para todos os envolvidos no manejo e gestão desse conjunto de artefatos.

Buscando sempre o processo de fortalecimento comunitário, muitas vezes são ignorados ou esquecidos os joguetes políticos envolvidos nessas relações internas às comunidades e, também, destas com as instituições externas. Embora tivessem conhecimento de que haviam muitos interesses políticos e econômicos envolvidos, muitas vezes parte da comunidade Agrovila e do grupo de pesquisadores e extensionistas da UFAM, enquanto categoria social, fomos ingênuos ao pensar, avaliar e procurar compreender somente os impactos causados pela presença da universidade em comunidades tradicionais, esquecendo que podiam ser menos agentes (sujeitos) e mais objetos de intrincadas redes e trâmites sociais existentes no âmbito dessas comunidades.

Ao final do processo, concluiu-se que era chegada a hora do grupo Tupé memo se retirar, deixando que a comunidade tomasse seus próprios rumos nas decisões quanto ao gerenciamento de seu patrimônio cultural. 


\section{CONSIDERAÇÕES FINAIS: REFLEXÕES E APRENDIZADOS}

De acordo com o IPHAN, alguns dos princípios que orientam a política federal de salvaguarda indicam que: 1) o patrimônio cultural é uma construção social que diz respeito a todos; 2) participação ativa dos atores sociais que produzem, mantêm e transmitem este patrimônio nos processos de identificação, reconhecimento e salvaguarda; 3) produção de informação e documentação como ação de salvaguarda em si mesma (o conhecimento como fundamento da salvaguarda); 4) descentralização e socialização de métodos e instrumentos com vistas à autonomia dos atores sociais e dos processos de preservação que conduzem; 5) articulação da política de salvaguarda com as políticas das áreas de educação, meio ambiente e desenvolvimento econômico e social; 5) visão global e integrada das dimensões material e imaterial do patrimônio cultural (SANT'ANNA, 2003).

Silva e Nunes Filho (2012, p. 14) enfatizam o envolvimento da coletividade na gestão do patrimônio arqueológico como sendo um instrumento eficaz quando o aparato legal não é suficiente para the efetuar a salvaguarda. Tendo em vista a ineficiência do IPHAN e demais órgãos fiscalizadores, existe a necessidade de parceria entre instituições e coletivos sociais para tais fins. Porém, o caso ora relatado problematiza como nem sempre a proposição ou imposição de programas de pesquisa ou educação patrimonial necessariamente redunda na salvaguarda do patrimônio. Relações políticas, ideologias, questões econômicas, individuais e coletivas irão pautar tais ações, mas podem ser colocadas enquanto oportunidades para questionamentos e contribuição para a política de preservação do patrimônio cultural, que deve ser tomada contextualmente para que possa garantir os interesses das comunidades envolvidas, a salvaguarda do patrimônio cultural e a legislação vigente.

$\mathrm{Na}$ arqueologia, têm sido cada vez mais frequente as formas de pensar nos coletivos sociais contemporâneos para entender não somente aspectos ligados ao passado, mas também para pensar sobre interações sociais e conflitos sociais no presente (para Amazônia, ver BEZERRA 2011, ROCHA et al., 2017, entre outros). Temas correlatos a este têm estado presentes em todos os últimos congressos da Sociedade de Arqueologia Brasileira, mostrando uma tendência nacional de discussões que há tempos permeiam diferentes correntes da arqueologia mundial (p. ex. STORCH, 1994, SHANKS e MACKENZIE, 1994; TILLEY, 1995; GNECCO, 2009). Ao referenciar tais discussões, Lima e Moraes (2013) ressaltam que a arqueologia, como uma prática social sintetizando a relação do passado com o presente que, sempre mediada por indivíduos, grupos ou instituições, a faz ter inevitavelmente um caráter ideológico e político. A exemplo de uma arqueologia crítica, concordamos com a proposição de Martinez (2005) de que ciência, ética e política 
Revista de Arqueologia Pública

estão altamente imbricados nas construções sobre o passado. Trabalhando na Colômbia, Hoffmann ressalta a "dialética entre interesses individuais e estratégias coletivas, mais ou menos explícitas, para responder a necessidades que pode ser tanto de ordem prática quanto política" (2000, p. 16, tradução nossa). Adicionamos, aqui, trazendo a discussão para em torno dos acervos e suas relações, que não somente a arqueologia é política, mas também a nossa atuação enquanto arqueológicos "faz política", e nem sempre (ou na maioria das vezes), não controlamos boa parte das variáveis em jogo. Mais do que isso, nossas proposições para o conhecimento e (consequente?) salvaguarda de um determinado acervo não necessariamente atendem aos diferentes interesses que envolvem sua formação, manutenção e apropriação.

Por fim, soma-se o atual quadro técnico dos órgãos gestores brasileiros, deveras insuficiente, à tarefa de acompanhar - localizada e contextualmente - situações em torno da gestão dos diferentes acervos, à luz de legislações que, por natureza, são generalizadoras. Embora o caso aqui relatado se configure como um claro conflito, considera-se fundamentais abordagens colaborativas entre gestores e os diferentes espectros da sociedade civil que permitam soluções criativas que resultem na efetiva salvaguarda e sobretudo na socialização desses bens públicos.

\section{AGRADECIMENTOS}

Agradecemos aos moradores da comunidade Agrovila Amazonino Mendes e demais comunidades da REDES do Tupé que se empenharam fortemente no projeto e sem os quais as ações aqui descritas não teriam sido possíveis. Agradecemos também aos diversos colaboradores do Grupo Tupé memo. A pesquisa teve financiamento inicial pelo Programa de Atividades Curriculares de Extensão (PACE) da Universidade Federal do Amazonas (UFAM) e, posteriormente, por meio de subprojeto aprovado pela pró-reitoria de extensão da UFAM dentro do programa PROEXT financiado pelo MEC-SESu. Contando ainda com autorização de pesquisa publicada no Diário Oficial da União de 05.10.2011 pelo Instituto do Patrimônio Histórico e Artístico Nacional (IPHAN), processo no..01450.011952/2011-84. 


\section{REFERÊNCIAS BIBLIOGRÁFICAS}

ANDRADE, Ellen Barbosa de et al. Gestão de unidade de conservação amazônica, mobilização social e envolvimento sustentável: tecendo o Tupé memo. Anais do Congresso Brasileiro de Gestão Ambiental e Sustentabilidade (CONGESTAS). João Pessoa, 2013.

ANDRADE, Ellen Barbosa de et al. Tecendo o Tupé: Extensão Universitária na Construção da Gestão Ambiental de uma Reserva de Desenvolvimento Sustentável Amazônica. Anais do 2 ํㅡㄹ Congresso Brasileiro de Extensão Universitária. Belo Horizonte, 2004.

BEZERRA, Márcia. As moedas dos índios: um estudo de caso sobre os significados do patrimônio arqueológico para os moradores da Vila de Joanes, ilha de Marajó, Brasil. Boletim do Museu Paraense Emílio Goeldi. Ciências Humanas, v. 6, n. 1, p. 5770, 2011.

BEZERRA, Marcia; NAJJAR, Rosana. Semióforos da Riqueza: um ensaio sobre o tráfico de objetos. Habitus. v. 7, n. 1, p. 289-307, 2009.

CALHEIROS, Catarina Ribeiro; MELO, Raul Perigo; LIMA, Helena Pinto. Patrimônio Cultural e Arqueológico na Reserva de Desenvolvimento Sustentável do Tupé, Manaus, Amazonas. In: 6 CEBEU - Congresso Brasileiro de Extensão Universitária, 2014, Belém. Diálogos de Extensão: saberes tradicionais e inovação.. Belém: UFPA, 2014.

CHATEAUBRIAND, Annunziata Donadio et al. REDES do Tupé: espacialização e informações das comunidades. Manaus: EDUA, 2009.

COSTA, Fernando; LIMA, Helena. Levantamento Arqueológico do Município de Manaus. Relatório encaminhado ao Ministério Público Federal e IPHAN, 1aㅡ Superintendência Regional. Manaus, 2006.

GODOY, Renata de. Arqueoturismo no cerrado e na Amazônia: Dois pedaços de um mesmo pote. Revista Arqueologia Pública, v. 9, n. 2 (12), p. 87-107, 2016.

FABIAN, Johannes. Colecionando pensamentos: sobre os atos de colecionar. Mana, v. 16, n. 1, p. 59-73, 2010.

CARNEIRO, Carla Gibertoni. Ações educacionais no contexto da arqueologia preventiva: uma proposta para a Amazônia. 2009. Tese de Doutorado. Universidade de São Paulo. 
GNECCO, Cristóbal. Caminos de la Arqueología: de la violencia epistémica a la relacionalidad. Boletim do Museu Paraense Emílio Goeldi. Ciências Humanas, v. 4, n. 1, p. 15-26, 2009.

GONÇALVES, Rafael Soares. Os impactos socioambientais da implementação da reserva de desenvolvimento sustentável do Tupé na comunidade Nossa Senhora do Livramento. 2011. Tese de Doutorado. PUC-Rio.

HOFFMANN, Odile. La movilizacion identitaria y el recurso a la memoria (Narno, Pacifico colombiano). Cristobal Gnecco y Marta Zambrano. Memorias hegemonicas, memorias disidentes. ICAN-Universidad del Cauca, p. 97-120, 2000.

HORTA, Maria de Lourdes et al. Guia básico de educação patrimonial. Brasília: IPHAN e Museu Imperial, 1999.

LIMA, Helena. História das Caretas: a Tradição Borda Incisa na Amazônia Central. Tese (Doutorado em arqueologia) Museu de Arqueologia e Etnologia da USP. São Paulo, 2008.

LIMA, Helena e ANDRADE, Ellen Barbosa de. Tupé: memória, cultura e identidade. Relatório de atividades elaborado pelo Museu Amazônico da Universidade Federal do Amazonas (UFAM) e apresentado ao Instituto do Patrimônio Histórico e Artístico Nacional (IPHAN), tratando de subprojeto realizado no âmbito do projeto Arqueologia e gestão patrimonial do baixo rio Negro.

LIMA, Helena. P.; MORAES, B. M. Arqueologia e Comunidades Tradicionais na Amazônia. Ciência e Cultura, v. 2, p. 39-42, 2013.

LIMA, Helena Pinto; MORAES, Bruno Marcos; PARENTE, Maria Tereza Vieira. "Tráfico" de material arqueológico, turismo e comunidades ribeirinhas: experiências de uma arqueologia participativa em Parintins, Amazonas. Revista de Arqueología Pública: Revista eletrônica do Laboratório de Arqueologia Pública da UNICAMP, n. 8, p. 61-77, 2013.

LIMA, Helena P. e PARENTE, M. T. Gestão do Patrimônio Arqueológico Amazônico. Manaus, IPHAN, 2009.

MANAUS, Diário Oficial do Município de Manaus. DECRETO N. 8044 de 25 de agosto de 2005. Ata de criação da Reserva de Desenvolvimento Sustentável do Tupé (REDES do Tupé). Número 1313, ano VI. Manaus, terça-feira, 30 de agosto de 2005. 


\section{Revista de Arqueologia Pública}

MARTÍNEZ, Víctor Manuel Fernández. Una arqueología crítica. Ciencia, ética y política en la construcción del pasado. Revista Digital Científica Independiente de Arqueología, p. 128, 2005.

NEVES, Eduardo. Levantamento Arqueológico da Área de Confluência dos Rios Negro e Solimões, Estado do Amazonas. Relatório de Atividades apresentado à FAPESP Museu de Arqueologia e Etnologia. São Paulo: Universidade de São Paulo, junho 1999 ago 2000 .

Levantamento arqueológico da área de confluência dos rios Negro e Solimões, Estado do Amazonas: Continuidade das escavações, análise da composição química e montagem de um sistema de informações geográficas. Relatório de Atividades apresentado à FAPESP - Museu de Arqueologia e Etnologia. São Paulo: Universidade de São Paulo, 2003.

Cronologias Regionais, Hiatos e Continuidades na História Pré-Colonial da Amazônia. Projeto Temático - FAPESP. Museu de Arqueologia e Etnologia. São Paulo: Universidade de São Paulo, 2005.

Arqueologia e Etnologia. São Paulo: Universidade de São Paulo, 2003.

Sob os tempos do equinócio: oito mil anos de história na Amazônia Central (6.500 AC—1.500 DC). São Paulo, Brazil: Universidade de São Paulo, 2012.

PALMEIRA, Jorge Ricardo Garcia et al. Cultura e manejo agroecológico: o reconhecer de parâmetros e limitações sustentáveis em comunidades tradicionais, o caso Colônia Central-Redes do Tupé. 2009.

PEIXOTO, Shirley Cintra Portela de Sá et al. Turismo e lazer em unidade de conservação: a experiência de São João do Tupé Redes do Tupé/AM. 2013

PEREIRA, Edithe; FIGUEIREDO, Silvio Lima. Arqueologia e Turismo na Amazônia: Problemas e Perspectivas. Cadernos do LEPAARQ - Textos de Antropologia, Arqueologia e Patrimônio. v. II, n³. Pelotas, RS: Editora da UFPEL. Jan/Jul 2005.

ROCHA, Bruna Cigaranç Jácome, C., Stuchi, F. F., Mongeló, G. Z., \& Valle, R. Arqueologia pelas gentes. Revista de Arqueologia, 26(1), 130-140, 2017. 


\section{Revista de Arqueologia Pública}

SANT'ANNA, Marcia. A face imaterial do patrimônio cultural: os novos instrumentos de reconhecimento e valorização. Memória e patrimônio: ensaios contemporâneos. Rio de Janeiro: DP\&A, p. 46-55, 2003.

SHANKS, Michaelç MACKENZIE, I. Archaeology: theories, themes and experience. In: Archaeological theory: progress or posture? Mackenzie, I. (ed.) Aldershot-Brookfield, Avebury. 1994.

SILVA, Ana Cristina Rocha; NUNES FILHO, Edinaldo Pinheiro. A proteção do passado: gestão participativa e educação patrimonial como instrumentos de salvaguarda do patrimônio arqueológico na Amazônia. In: Planeta Amazônia: Revista Internacional de Direito Ambiental e Políticas Públicas. Macapá, n. 4, p. 13-21, 2012

SILVA, Carlos Augusto. Relatório do acompanhamento arqueológico na área onde está sendo implantada a eletrificação rural de rede monofásica nas comunidades Agrovila Amazonino Mendes, Julião e Livramento (Programa Luz para Todos). Relatório de atividades encaminhado ao IPHAN/AM. Manaus, 2008. 55p.

SIMÕES, Mário. Contribuição à arqueologia dos arredores do baixo Rio Negro. In: Programa Nacional de Pesquisas Arqueológicas 5. Publicações Avulsas do Museu Paraense Emilio Goeldi, v. 26, p. 165-188. Belém, 1974.

STORCH, J. Arqueología y política: en busca de la inocencia perdida. Arqritica, v. 8, p. 2-3, 1994.

THIOLLENT, Michel. Metodologia da pesquisa-ação. In: Metodologia da pesquisa-ação. Cortez, 2011.

TILLEY, C. Archaeology as socio-political action in the present. In: Critical traditions in contemporary archaeology. Pinsk, V. \& Wylie, A. (eds.). University of New Mexico Press, Albuquerque. 1995.

TROUFFLARD, Joanna. Abordagem da prática colecionista através de um conjunto de peças marajoara do Museu Nacional de Etnologia em Lisboa (Portugal). In: Amazônica 3 (1): 142-168, 2011.

TROUILLOT, Michel-Rolph. Transformaciones globales: La antropología y el mundo moderno. Editorial Universidad del Cauca, 2011. 